(2) Open Access Full Text Article

REVIEW

\title{
Impact of Weight Change in Adults with Type 2 Diabetes Mellitus: A Literature Review and Critical Analysis
}

This article was published in the following Dove Press journal: ClinicoEconomics and Outcomes Research

\author{
Moshe Fridman (1D \\ Mariann E Lucas ${ }^{2}$ \\ Yurek Paprocki ${ }^{3}$ \\ Tam Dang-Tan ${ }^{4}$ \\ Neeraj $N$ lyer (iD ${ }^{5}$
}

'Biostatistics, AMF Consulting, Los Angeles, CA, USA; ${ }^{2}$ Information Science, Scientific Analytics, Novo Nordisk Inc, Plainsboro Township, NJ, USA; ${ }^{3}$ Medical Affairs, Novo Nordisk Inc, Plainsboro Township, NJ, USA; ${ }^{4}$ Medical Affairs, Novo Nordisk Inc, Plainsboro Township, NJ, USA; ${ }^{5} \mathrm{HEOR}$ Strategy \& Evidence Generation - Diabetes, Novo Nordisk Inc, Plainsboro Township, NJ, USA
Correspondence: Neeraj $\mathrm{N}$ lyer Novo Nordisk, Inc, 800 Scudders Mill Road, PlainsboroTownship, NJ 08536 , USA

Tel + I 6095788157

Email nriy@novonordisk.com
Objective: Weight reduction is a key component of diabetes management in adults with type 2 diabetes mellitus (T2DM), yet the benefits of weight loss in T2DM patients have been difficult to quantify. We examined the medical literature regarding the relationships between weight change and 1) glycemic control and 2) cost and resource use.

Methods: Systematic searches were conducted in the electronic databases Embase, MEDLINE, and the Cochrane Database of Systematic Reviews to identify publications regarding the impact of weight change on T2DM outcomes from 2007 onward. Identified publications were screened for relevance against predefined eligibility criteria, and methodological approaches and results were extracted. Evidence for the impact of weight change on outcomes was evaluated and used to identify strengths, limitations, and gaps in the current literature.

Results: The number of studies meeting eligibility criteria for each outcome was: glycemic control $(n=38)$ and cost and resource use $(n=11)$. The relationship between weight change and glycemic control was dependent on the interplay of multiple factors, eg, the weight loss interventions employed, the antidiabetic medication classes used, the time horizon, and baseline BMI and glycemic control. With respect to cost and resource use, the review indicated that savings were associated with weight loss, and increased costs were associated with weight gain.

Conclusion: Studies regarding weight change in T2DM patients demonstrated varying effects on glycemic control and a positive association with costs and resource use, where weight loss was associated with decreased costs and resource use. Future studies may be able to clarify these relationships.

Keywords: type 2 diabetes, overweight/therapy, obesity/therapy, weight loss, cost, resource utilization, economics

\section{Plain Language Summary}

Weight reduction is a key component of diabetes management in patients with Type 2 diabetes mellitus. The evaluation of the benefits of weight loss interventions has been difficult, largely because of the many inter-relationships among these interventions, metabolic factors, and human behaviors.

We report on studies that examined the relationship of weight change and glycemic control $(n=38)$ and cost and resource use $(n=11)$. The relationship between weight change and glycemic control was not consistent and depended on other factors, such as the weight loss interventions employed, antidiabetic medication classes used, time period for weight change and outcome studied, and baseline Body Mass Index (BMI) and glycemic control. 
For cost and resource use, the review indicated that savings was associated with weight loss and increased costs associated with weight gain.

We highlight the potential to improve research study designs and methodologies to better understand the benefits of weight loss and the detriments of weight gain.

\section{Introduction}

According to the American Diabetes Association, an estimated 24.7 million people in the United States (US) are diagnosed with diabetes, representing approximately $9.7 \%$ of the adult population. ${ }^{1}$ Cases of diabetes are expected to continue to rise markedly, both in the US and worldwide. ${ }^{2,3}$ In 2017, the average medical expenditures in the US were 2.3 times higher in people with diabetes compared with those without diabetes, and there were an estimated 277,000 premature deaths attributed to diabetes. ${ }^{1}$ Type 2 diabetes mellitus (T2DM) accounts for 90-95\% of all cases. ${ }^{4}$

Per the Centers for Disease Control and Prevention, $87.5 \%$ of US adults with diabetes were overweight or obese. ${ }^{4}$ The 2018 position statement of the American Diabetes Association (ADA) and the European Association for the Study of Diabetes (EASD) on the management of type 2 diabetes in adults states that "for those with obesity, efforts targeting weight loss, including lifestyle, medication, and surgical interventions, are recommended"s Weight reduction improves insulin sensitivity and preserves beta-cell function, leading to decreased fasting and postprandial glucose levels, and improved glycosylated hemoglobin (HbAlc) results. ${ }^{6}$ Balancing adequate glycemic control and obesity risk is a challenge for clinicians when choosing an antidiabetic medication regimen, since several antidiabetic medications are associated with weight gain., ${ }^{7,8}$

Multiple clinical studies have attempted to identify pharmaceutical, surgical, or lifestyle interventions that can achieve weight loss in the T2DM population. ${ }^{9-11}$ The pathophysiology of T2DM involves elaborate relationships between a variety of organ systems, each with their associated hormones and feedback loops. Adiposity increases insulin resistance, leading to the development of T2DM, or worsening symptoms. ${ }^{12}$ In turn, weight loss can result from a wide range of interventions (eg, diet, exercise, medications, surgery), with each intervention potentially having a different impact physiologically and psychologically.

The purpose of this review was to assess the recent medical literature regarding the effects of weight change in the T2DM population, with a focus on identifying the gaps and limitations within the current evidence. We used examples to determine how to better understand these limitations and overcome these constraints in the future.

\section{Materials and Methods}

A scoping literature review ${ }^{13}$ was conducted to identify studies of adult T2DM patients reporting relationships between weight loss and the outcomes of interest: 1) glycemic control, and 2) cost/resource use. Search queries were performed for literature published in the English language from January 1, 2007, through May 29, 2017, utilizing PubMed, EMBASE, and the Cochrane Database for Systematic Reviews. The Cochrane Database was searched separately. Search strings are provided in Supplementary Appendix 1.

Eligibility criteria were identified in advance (Table 1). Studies on cancer populations or patients who underwent bariatric surgery were excluded. These criteria were first applied to the title and abstract of an article in Round 1 of study selection. Citations were identified in Round 1 if they included adult individuals with T2DM and had data regarding weight change and the outcome of interest. Two reviewers read and selected all the citations. If the relevance of a citation was disputed, it was carried forward to Round 2. During Round 2, the full text of the potentially relevant citations was examined by 2 reviewers. Discrepancies were resolved by consensus, or if needed, discussion with the research team. Relevant data from eligible publications were entered into a data extraction table and verified by a second reviewer. For cost, all amounts extracted and reported are expressed in US dollars.

\section{Results \\ Study Selection}

The PRISMA diagrams of the flow of citations through the selection process for the two outcomes are presented in Figures 1 and 2. ${ }^{14}$ There were 786 glycemic control citations and 419 cost/resource use citations identified from the PubMed and Embase electronic databases. Of 318 articles retrieved from the Cochrane Database that pertained to diabetes, none was included in either of the final datasets. In general, these studies did not meet inclusion criteria because they did not evaluate weight change. The final datasets included 38 articles for glycemic control $^{15-52}$ and 11 articles for cost/resource use. ${ }^{50-60}$ Three articles were included in both datasets. ${ }^{50-52}$ 
Table I Eligibility Criteria for the Review

\begin{tabular}{|c|c|c|}
\hline Criteria & Include & Exclude \\
\hline Population & $\begin{array}{l}\text { Adults (aged } \geq 18 \text { years) with type } 2 \\
\text { diabetes }\end{array}$ & $\begin{array}{l}\text { - Pediatric populations } \\
\text { - Animal populations } \\
\text { - Pregnant populations } \\
\text { - Studies reporting results only for mixed populations (part of the population } \\
\text { - } \text { not meeting inclusion criteria) } \\
\text { Patients with cancer }\end{array}$ \\
\hline $\begin{array}{l}\text { Intervention and } \\
\text { comparators }\end{array}$ & $\begin{array}{l}\text { Weight change in relationship to one of } \\
\text { the outcomes }\end{array}$ & $\begin{array}{l}\text { - Weight change due to surgery } \\
\text { - Interventions with antihyperglycemics not approved by the United States } \\
\text { Food and Drug Administration }\end{array}$ \\
\hline Outcomes & $\begin{array}{l}\text { - Glycemic control } \\
\text { - Cost and resource use }\end{array}$ & \\
\hline Study design & $\begin{array}{l}\text { - Observational studies } \\
\text { - Clinical trials } \\
\text { - Database claims } \\
\text { - Modeling studies } \\
\text { - Meta-analyses }\end{array}$ & $\begin{array}{l}\text { - Narrative and systematic reviews without meta-analysis } \\
\text { - Editorials, news } \\
\text { - Practice guidelines } \\
\text { - Case studies }\end{array}$ \\
\hline
\end{tabular}

\section{Studies on the Association Between Weight Loss and Glycemic Control}

Thirty-eight relevant published articles were identified (Table 2). These studies were of the following types: 16 post hoc analyses of randomized controlled trials (RCT); 13 retrospective observational cohort studies; 5 prospective cohort studies, 4 of which included an intervention, ie, pharmaceutical $(n=3)$ or lifestyle $(n=1) ; 1$ post hoc analysis of an observational cohort study; 1 study that created a model to describe the relationship between changes in weight and glycemic control; 1 RCT; and 1 discrete choice experiment.

A range of measures for weight change was found. Changes in weight were described in kilograms $(\mathrm{kg})$, body mass index (BMI), percent body fat, and by percent changes in these measurements. These measures were often collapsed into categorical variables such as weight loss/weight gain/weight stability, weight change patterns

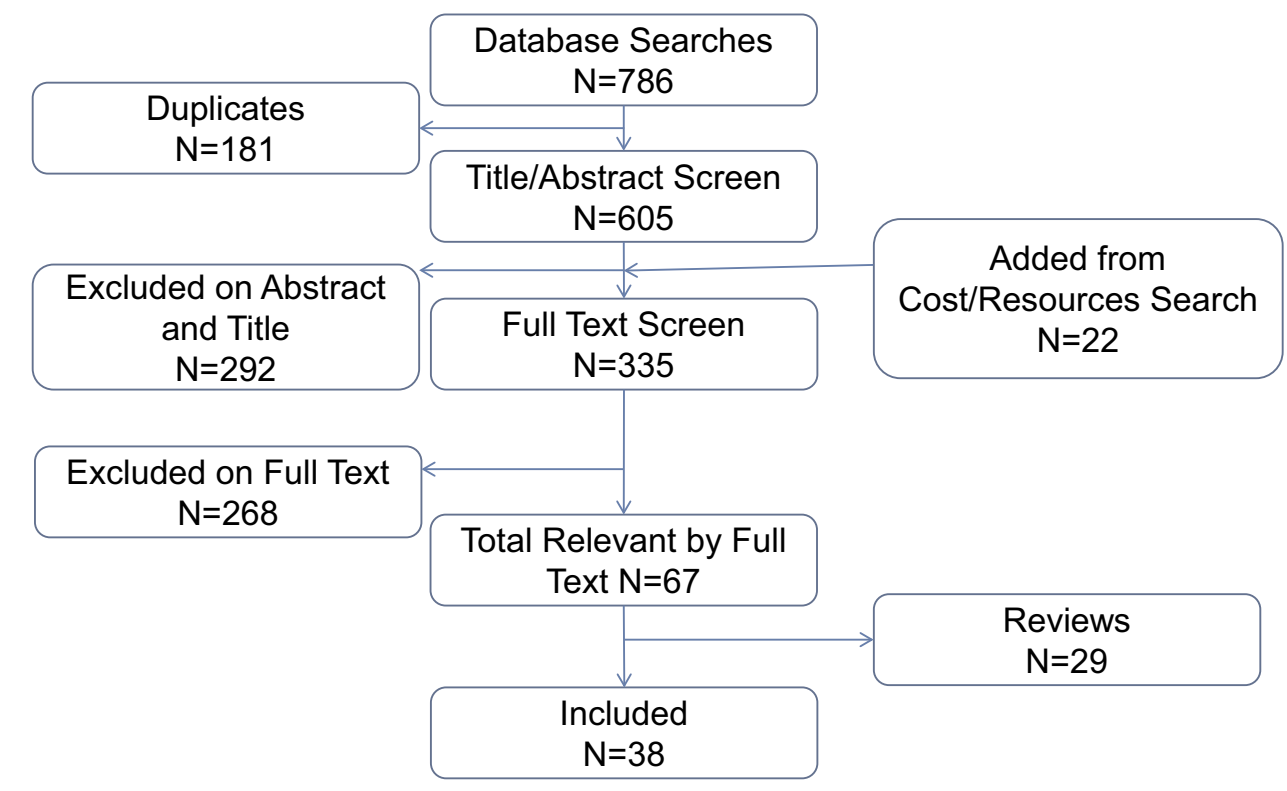

Figure I Flowchart of the process of determining eligible studies regarding T2DM weight loss and glycemic control. 


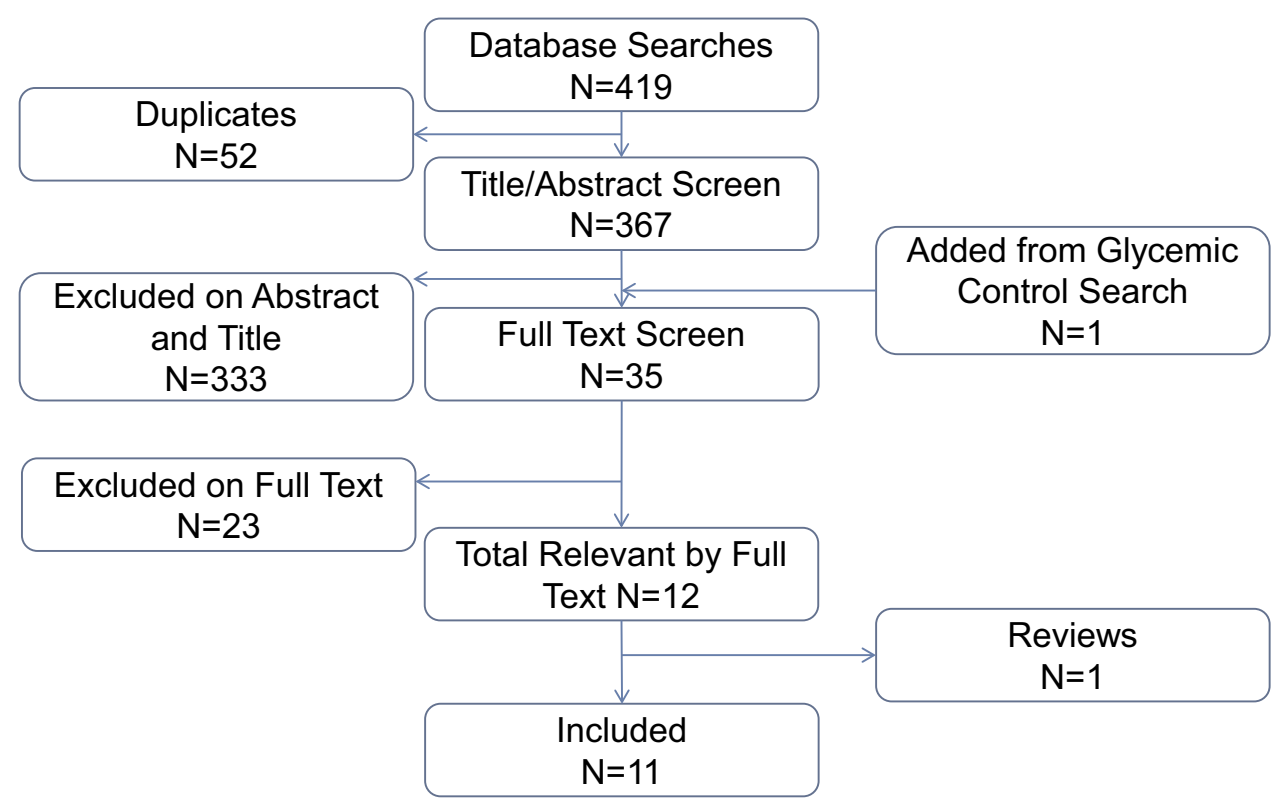

Figure 2 Flowchart of the process of determining eligible studies regarding T2DM weight loss and cost/resource use.

(ie, weight fluctuations over time), tertiles/quartiles of weight change, or were classified using a minimal loss/ gain of a specific amount of weight, eg, $\geq 3 \%$ change, $\geq 5$ $\mathrm{kg}$, or BMI $\geq 1 \mathrm{~kg} / \mathrm{m}^{2}$. The composite outcome of weight gain or loss and a specified HbAlc goal was also used. Time periods for weight measurements varied across studies, some focusing on short term (eg, 12 weeks), and others on sustained weight loss (eg, 2 years).

The most common measure of glycemic control was HbAlc, which was expressed in both percent of total hemoglobin and in mmol/L. Various HbAlc goals were used as study endpoints. Other measures included fasting glucose levels, and one paper used the frequency of hypoglycemic episodes. ${ }^{24}$ For several studies, glycemic control was treated as an explanatory variable for weight change, as opposed to an outcome. ${ }^{15,27,31,35,39,44}$

The reported relationships between weight change and glycemic control were not consistent across the 38 studies. The wide variation in findings was due to the heterogeneity in (1) the factors described above, (2) the type of interventions and medication classes used by the patients in different studies, and (3) the period of observation. Some studies demonstrated a positive relationship, eg, that weight loss was associated with a lower HbA1c, some demonstrating a negative relationship, eg, that weight loss was associated with a higher $\mathrm{HbA1c}$, and some demonstrating that this relationship may be positive or negative depending on the time period studied and the intervention used.

\section{Studies Showing a Positive Association}

Real-world studies that reported a positive relationship included Davis et al, ${ }^{51}$ who found that $\geq 5 \%$ loss over 4 years was associated with measurably improved glycemic control at 4 years. Another real-world study was conducted by McAdam-Marx et al. ${ }^{16,17,40}$ The authors found that, among patients who were newly treated or starting a new class of medications, those who lost $\geq 3 \%$ of their body weight were more likely to attain their $\mathrm{HbAlc}$ goal. In a post hoc analysis of an RCT, Wing et $\mathrm{al}^{45}$ had similar results.

In a meta-analysis, Franz et a ${ }^{48}$ found that $5 \%$ weight loss appeared necessary to have beneficial effects on glycemic control, while acknowledging that most lifestyle interventions were not able to achieve this amount of weight loss. Carter et $\mathrm{al}^{21}{ }^{21}$ in a study comparing two types of energy-restriction diets, found that a $1 \%$ change in body fat accounted for a $3 \%$ change in HbAlc. Gummeson et $\mathrm{al}^{49}$ conducted a meta-analysis to develop a model suggesting that, on average, for each $\mathrm{kg}$ of weight loss, there was an $\mathrm{HbA} 1 \mathrm{c}$ reduction of 0.1 points, and that $\mathrm{HbA1c}$ lowering was greater when baseline glycemic control was poor.

\section{Studies Showing a Negative Association}

Other studies demonstrated and quantified a negative relationship, ie, that weight gain was associated with a lower $\mathrm{HbA1c}$ in patients. This is consistent with the often-cited association between weight gain and insulin use, ${ }^{8}$ although 
Table 2 Summary of Selected Articles with Reference Numbers

\section{Number of included articles}

- The study included 46 articles with the following number of articles per category:

- Glycemic control: 38

- Cost and resource use: II

- Three studies were in both datasets (Nichols et al, ${ }^{50}$ Davis et al, ${ }^{51}$ Mohamed et al) ${ }^{52}$

- Nearly all studies relied on unique study populations. The following studies were exceptions. Two McAdam-Marx articles ${ }^{16,17}$ relied on overlapping study populations from the Geisinger Health System.

- Gummeson et al, ${ }^{49}$ Franz et al, ${ }^{48}$ and Zinman et al ${ }^{47}$ were metaanalyses.

\section{Study design}

- Glycemic Control Studies

- Post hoc analyses of RCTs: $16^{19-21,24,26,31,32,35-37,41,43,45,47-49}$

- Retrospective observational cohort studies: $13^{16-18,22,23,28,}$ $29,34,38,40,42,44,50$

- Prospective observational cohort studies: $5^{30,33,39,46,51}$

- Post hoc analyses of prospective cohort studies: $1^{27}$

- Simulation model: $1^{15}$

- Discrete choice experiment: $I^{52}$

- RCT: I $^{25}$

- Cost Studies

- Retrospective observational cohort studies: $6^{50,53-56,60}$

- Simulation model: $3^{57-59}$

- Prospective observational cohort studies: $1^{51}$

- Cross-sectional surveys: $1^{52}$

\section{Study population}

- Glycemic Control Studies

- T2DM cohort or registry patients: $10^{18,2,3,9,22,23,33,38,44,51}$

- T2DM cohort males only: ${ }^{46}$

- T2DM cohort self-reported: $2^{21,52}$

- T2DM cohort employees: $2^{34,40}$

- T2DM EMR: $2^{16,29}$

- T2DM EMR + claims: $2^{17,50}$

- T2DM RCT or pooled studies: $15^{15,19,24,26,31,32,35-37,41,43,45 \text {, }}$ 47,48

- T2DM RCT for elderly: $\mathrm{I}^{20}$

- T2DM RCT for cardiac patients: $I^{25}$

- T2DM studies for insulin naïve patients: $2^{24,27}$

- T2DM study for patients who resolved T2DM: $1^{42}$

- Cost Studies

- T2DM cohort or registry patients: $2^{51,60}$

- T2DM cohort self-reported: $1^{52}$

- T2DM cohort employees: $1^{57}$

- T2DM EMR + claims: $5^{50,53-56}$

- T2DM simulation model for Medicare patients: $I^{58}$

- T2DM simulation model for patients in a weight loss program: $1^{59}$

\section{Weight change measures}

- Glycemic control Studies

- Percent body fat: $\mathrm{I}^{21}$
Table 2 (Continued).

- Percent total weight: $8^{16,17,33,34,40,45,48,51}$

- BMI: $I^{42}$

- Quartiles/Tertiles of weight change: $2^{19,41}$

- Composite outcome with HbAlc: $2^{25,26}$

- Kilograms: $18^{15,22-24,27,30,32,35-39,43,44,46,49,52}$

- Weight lost vs gained/maintained: $5^{20,28,31,47,50}$

- Weight change pattern: $2^{18,29}$

- Cost Studies

- Percent total weight: $5^{51,53-55,58}$

- Weight lost vs gained/maintained: $2^{50,56}$

- BMI: $1^{60}$

- Kilograms: $3^{52,57,59}$

\section{Outcome measures}

- Glycemic control Studies

- Composite outcome including HbAlc and weight gain/loss: $5^{25,26,28,47,56}$

- FPG or FBG and HbAlc: $7^{19,34,37,38,46,51}$

- HbAlc: $18^{16-18,20-23,29,30,33,36,40-43,46,48,49}$

- HbAlc as a predictor: $6^{15,27,31,35,39,44}$

- HOMA-IR: I $^{30}$

- Hypoglycemic events: ${ }^{24}$

- Treatment attributes, including glycemic control: $1^{52}$

- Cost Studies

- Costs (variety of definitions): $11^{50-60}$

- Resource use (variety of definitions): $2^{53,54}$

Type of analysis

- Glycemic control Studies

- Student's t-testing: $1^{51}$

- Adjusted means: $2^{38,40}$

- Correlation: $5^{30,32,36,43}$

- Descriptive only: $5^{19,22,23,46,50}$

- Linear regression: $12^{21,24,27,28,31,33-35,37,39,41,44}$

- Logistic regression: $7^{18,20,25,26,29,42,45}$

- Meta-analysis: $3^{47,48}$

- Simulation models: $I^{15}$

- Structural equation modelling: $2^{16,17}$

- Discrete choice: $1^{52}$

- Cost Studies

- Linear regression: $6^{50,51,53-56}$

- Simulation model: $3^{57-59}$

- Cross-sectional survey: $1^{52}$

- Descriptive only: $1^{60}$

Abbreviations: $\mathrm{HbAlc}$, hemoglobin $\mathrm{HbAlc}$; BMI, body mass index; $\mathrm{EMR}$, electronic medical record; FBG, fasting blood glucose; FPG, fasting plasma glucose; HOMAIR, Homeostasis Model Assessment-Insulin Resistance; RCT, randomized controlled clinical trial; T2DM, type 2 diabetes mellitus.

it was not always possible to distinguish the results by drug classes for the studies included in this report. The study by Cohen et $\mathrm{al}^{23}$ was among the real-world studies demonstrating this result. The investigators followed outpatients for over 5 years, dividing them into those on oral 
medications vs oral medications plus insulin, noting that the insulin group increased weight upon insulin initiation with a reduction in $\mathrm{HbAlc}$. Watson et $\mathrm{al}^{44}$ also examined weight gain at insulin initiation, finding weight gain highest in those with poorest control and that higher BMI at baseline was associated with less weight gained. Janghorbani et $\mathrm{al}^{38}$ followed outpatients for up to 15 years, also demonstrating that those who gained weight had better glycemic control, although there was no description of or adjustment for medication class.

Several post hoc analyses of RCTs also demonstrated this negative relationship, that weight gain was associated with a lower HbAlc. Glass et $\mathrm{al}^{32}$ in a study comparing exenatide and insulin, found that patients on exenatide achieved an average $2 \mathrm{~kg}$ weight loss and a $1 \%$ decrease in $\mathrm{HbA1c}$, while patients on insulin had a $2 \mathrm{~kg}$ weight gain and a $1 \%$ decrease in $\mathrm{HbA} 1 \mathrm{c}$. Jacob et $\mathrm{al}^{37}$ pooled data from studies using insulin and also found weight gain to be associated with a drop in HbAlc.

\section{Patterns of Weight Loss and Glycemic Control}

Several real-world studies attempted to describe weight change patterns over time. These studies generally found that the relationship between weight change and glycemic control was not only associated with diabetes medication classes but was also dynamic throughout a patient's life course. Study results were dependent on the window of the study period. Jansen et $\mathrm{al}^{39}$ followed patients starting biphasic insulin for 3 years, noting that in the first 9 months, patients gained on average $0.5 \mathrm{~kg} /$ month. They found that $12 \%$ of the variation in documented weight gain was associated with a drop in $\mathrm{HbAlc}$, and that those with higher baseline obesity had less weight gain. However, in the following period (9-36 months), bodyweight increased at $0.1 \mathrm{~kg} /$ month, unrelated to changes in glycemic control. In patients followed for 2 years after diagnosis, Aucott et $\mathrm{al}^{18}$ described two weight change patterns that were associated with poor glycemic control in patients in a large diabetes registry: 1) gaining weight, and 2) being weight stable with weight change variability. Feldstein et $\mathrm{al}^{29}{ }^{29}$ in a retrospective cohort study of patients with newly diagnosed T2DM, stressed the importance of initial weight loss, finding that those who lost weight in the first 18 months had improved glycemic control despite regaining weight in the next 18 months.

With respect to post hoc analyses of weight change patterns, similar points were made. First, weight change patterns appeared to parallel what was found in the real- world studies. Neiberg et $\mathrm{al},{ }^{41}$ in a post hoc analysis of an RCT using data from the Look AHEAD lifestyle intervention study, showed that greater first year month-to-month weight losses (top tertile) were predictive of greater $\mathrm{HbA1c}$ reduction at 4 years. Second, the initiation phase of insulin treatment was associated with weight gain and improved glycemic control. Fonseca et $\mathrm{al}^{31}{ }^{31}$ in another post hoc analysis of an RCT, found this weight gain in the insulin initiation phase especially true if the baseline $\mathrm{HbAlc}$ was elevated. Huizenga et $\mathrm{al}^{35}$ in a prospective observational ancillary study to an RCT, specifically studied the trajectories of patients who underwent intensive control with insulin vs non-insulin treatments after control was achieved, ie, essentially avoiding contamination by the initiation of insulin. They found that at the end of the 2-year study, insulin users had less weight gain compared to non-insulin users.

\section{Studies on the Association Between Weight Loss and Healthcare Cost and Resource Use}

The literature search resulted in 11 relevant published articles, of which 6 were retrospective observational, 1 was a prospective observational cohort study, 3 were based on simulation models, and 1 was a discrete choice experiment (Table 2). Five of the retrospective studies used claims and/or EMR administrative data and one used epidemiological data collected at primary care centers. The prospective study used data collected from an observational diabetes study.

As found with research that reported on glycemic control and weight loss summarized in the previous section, a review of the healthcare cost and resource use papers identified a range of measures for both weight change and cost. For most studies, healthcare costs included outpatient and inpatient medical costs, labs costs and pharmacy costs (both all-cause and diabetes-related); however, Sabale et $\mathrm{al}^{60}$ excluded medication costs. The period of measurement of costs also varied by study, with most studies considering the annual costs for the year after the weight change evaluation period, effectively assuming a future effect of weight change on cost. Sabale et $\mathrm{al}^{60}$ also considered a longer 3year cost follow-up but used overlapping annual periods for weight change and cost measurements. The 3 simulation studies examined lifetime costs.

We found that patients who gained weight generally had higher costs compared to those in weight-loss or weight-neutral cohorts. Five studies ${ }^{49,52-54}$ used administrative data (eg, insurance and pharmacy claims data), that 
may have included a link to electronic medical record (EMR) data, to assess the relationship between weight change and costs. Bell et al ${ }^{54}$ performed a retrospective cohort study in patients in a health maintenance organization (HMO) who were receiving at least one oral antidiabetic medication $(91 \%$ on metformin only during the study period) to measure all costs and diabetes-specific costs for T2DM patients losing $>3 \%$ or gaining $>3 \%$ compared to weight-neutral patients in the first 6 months of the study. The weight-loss cohort incurred lower costs per year, primarily due to lower medical costs from reduced utilization. Weight reduction was associated with approximately $\$ 2200$ and \$440 lower annual all-cause and T2DM-specific costs $(p<0.05)$, respectively. Weight gain was associated with a significant increase in all-cause costs of $\$ 3400$ per year. Differences in T2DM-specific costs between the weight-gain and the weight-neutral cohort did not reach significance levels.

Blak et $\mathrm{al}^{55}$ had similar results using administrative databases in the United Kingdom. Compared with the weight-neutral group (ie, $<3 \%$ weight change), weight gain over 6 months was subsequently associated with increased diabetes medication prescribing and contact with primary care clinicians, and with increased diabetes costs in primary care and in total spending. However, weight gain was not associated with more or longer allcause hospital admissions. By contrast, higher weight loss was associated with substantially increased odds of allcause hospital admission, length of stay and total costs but not with diabetes primary care spending. These higher costs associated with weight loss differ from the findings of Bell et al, ${ }^{54}$ who found inpatient costs lowered. The inclusion of older, more severe T2DM patients in Blak et $\mathrm{al}^{55}$ would increase the likelihood that some of these patients were fragile and suffered severe complications requiring hospitalization following intentional or unintentional weight loss during the identification period.

To avoid the potential bias caused by unintentional weight loss, Nichols et $\mathrm{al}^{50}{ }^{50}$ in another administrative data study, focused on weight stability, and eliminated those $\geq 85$ years old. Patients who maintained weight within $5 \%$ of baseline over the 4-year study period experienced a reduction in costs of about $\$ 400$ regardless of HbAlc. In contrast, patients who gained $>5 \%$ of baseline weight and had mean $\mathrm{HbA} 1 \mathrm{c} \geq 7 \%$ had an increase in costs of $\$ 1473(p<0.001)$. Those who gained $>5 \%$ of their baseline weight with mean $\mathrm{HbA1c}<7 \%$ had a modest increase in costs ( $\$ 387$, non-significant).
Mukerjee et $\mathrm{al}^{53}$ conducted an administrative data study among patients with T2DM and found that weight loss over a short-term (6-month) period was associated with decreased diabetes-specific pharmacy costs over the subsequent 12 months. In the subset of patients who had obesity and had no previous cardiovascular disease, weight loss was also associated with decreased all-cause pharmacy costs, diabetes-specific medical costs, and diabetesspecific total healthcare costs.

Yu et $\mathrm{a}^{56}$ examined a linked HMO database of administrative data and EMR data in a retrospective cohort study to compare both 1-year total and diabetes-specific healthcare costs in patients who did and did not have weight gain over a 6-month period. This work was consistent with most of the above findings in that weight change was positively associated with total costs, but added the finding that, for DM-specific costs, it was important to model weight gain and weight loss separately. They found that every one percentage point weight loss was associated with a $5.8 \%$ or $\$ 131$ cost decrease $(p<0.01)$, while one percentage point weight gain was insignificantly related to a $0.40 \%$ or $\$ 9$ cost increase.

With respect to other research designs, Davis et al, ${ }^{51}$ in a prospective observational cohort study, found lower total medication costs for those with a $5 \%$ loss of initial body weight over 4 years. They demonstrated that weight loss during follow-up was associated with cerebrovascular disease at baseline, highlighting the above concern regarding the identification of intentional vs unintentional weight loss.

Sabale et al, ${ }^{60}$ in a retrospective analysis of an epidemiological dataset, identified newly diagnosed patients in primary care clinics and followed them annually with BMI measurement. Outpatient, inpatient, and laboratory costs over 3 years were documented. Patients were assigned to weight change categories based on $\geq 1$ BMI unit increase, $<1$ BMI unit change, and $\geq 1$ BMI unit decrease (roughly equivalent to a $3 \%$ change in body weight). Patients were assigned a pattern for the entire 3 years. Mean annual and 3-year cumulative healthcare costs were estimated for each pattern. Weight stability was the most common pattern over 3 years and it was associated with the lowest healthcare costs.

Meads et al,${ }^{57}$ Thorpe et al, ${ }^{58}$ and Trueman et al ${ }^{59}$ each used simulation models to examine short-term and lifetime costs for weight change. None of these studies exclusively studied T2DM patients. Two of these studies ${ }^{57,59}$ used data from weight loss intervention programs and found cost savings associated with enrollment in the program. The third, ${ }^{58}$ using data from the Diabetes Prevention Program to populate their 
models, found cost savings associated with weight loss. This last study assumed that weight loss was permanent, and also checked a scenario where weight loss was temporary for $90 \%$ of the individuals, still finding that cost savings would occur.

\section{Discussion}

This review identified 38 studies describing the association of weight change with the outcome of glycemic control and 11 describing the association of weight change with healthcare cost/resource use. Although studies regarding the relationship between weight change and glycemic control showed a range of associations, the relationship between weight loss and cost/resource use was generally positive, with weight gain associated with higher costs and weight loss associated with lower costs.

The implications must be examined within each individual study context and may not be generalizable. For example, among the studies that focused on the impact of weight loss on glycemic control, a variety of weight loss patterns were described, illustrating that simple linear relationships did not consistently reflect what actually occurred. Several factors may have impacted the interpretation of the results, including not only the duration of T2DM diagnosis [which has been found to be unreliable as a proxy for T2DM severity], ${ }^{61}$ the baseline BMI and HbAlc, and the treatments used, but also the time period evaluated. Generally, the weight loss period evaluated was concurrent with the change in glycemic control, ie, the entire time period was used to evaluate both the predictor and outcome variables. Demonstration of a causal effect between weight change and the outcome would require that the weight change preceded the outcome. Feldstein et al, ${ }^{29}$ Jansen et al, ${ }^{39}$ and Neiberg et $\mathrm{al}^{41}$ each demonstrated the importance of calculating weight change over an "initial" period, preceding the time of measuring the change in glycemic control, not only because time of measurement may impact the associations but also because of changes in both weight and glycemic control that may occur after 9-18 months of treatment if a change in treatment is involved.

Although most studies attempted to control for the medication class used by patients, there was much potential for misclassification, particularly in real-world studies over the long term. These concerns are warranted, given the known and often opposite effects of insulin and other medication classes on the relationship between weight loss and glycemic control.

The cost review demonstrated a generally positive relationship between weight change and costs. This result was consistent with evidence that weight gain is linked to increased insulin resistance and consequent initiation of insulin treatment, ${ }^{10}$ therefore requiring more healthcare services. Weight gain is also linked to worsening of cardiovascular risk factors such as blood pressure and elevated cholesterol, ${ }^{62}$ requiring closer patient monitoring and additional medications. Several of the administrative data studies suggested that weight loss may not have positive associations with costs in older patients ${ }^{50,54,55}$ or those with cardiovascular disease. $^{53}$ The concept of intentional versus unintentional weight loss is not easily distinguished in such studies, and sub-analyses may be necessary to quantify the bias encountered because of weight loss due to hospitalization and illness.

The reviewed studies indicate that weight gain, weight loss, and weight stability may all have different effects on healthcare spending, and that perhaps longer-term follow-up is required to collect more accurate information regarding weight change patterns. The importance of considering weight change patterns is supported by a recent study that examined real-world weight change patterns in a large longitudinal electronic patient database and included patients who had obesity at baseline (BMI $\geq 30 \mathrm{~kg} / \mathrm{m}^{2}$ ), did not gain weight during the first 6 months weight change evaluation period and had a minimum of 2.5 years of follow up. ${ }^{63}$ It was found that weight cycling and regain were common after an initial weight loss and that continued weight loss was more likely among patients who initially lost more weight. Longitudinal data may provide stronger long-term evidence and help in overcoming these limitations with more robust study designs that include adjustment for baseline patient characteristics and better account for variation in weight change and clinical outcomes over time.

A salient limitation of both the administrative data studies and simulation models was their generalizability to the complex care scenarios that patients with T2DM experience. In general, these studies used a government or payer perspective, failing to consider the potential benefits that might accrue to patients, such as improved quality of life, or fewer disability days, or improved glycemic control.

An important finding of this review was that the study designs evaluating the relationship between glycemia and weight change need further development. The 2018 position statement of the ADA and the EASD acknowledges the key knowledge gap regarding

understanding the biology, psychology, and sociology of obesity to identify pharmacological, behavioral, and 
political approaches to preventing and treating this principal cause of type 2 diabetes. $^{5}$

Since RCT are designed to determine the effect of the intervention (often a drug) on outcomes, these studies are difficult to use for the independent assessment of the impact of weight change on diabetes outcomes, such as HbA1c. The creation of a cohort of T2DM patients (such as large longitudinal patient systems) that have real-world weight loss and glycemic control measurements unassociated with a specific intervention assignment would improve the interpretability, quantification, and generalizability of the connection between weight loss and outcomes in T2DM patients. ${ }^{64}$ Figure 3 summarizes the potential relationships derived from this literature review. The key methodological barriers identified in the literature were:

Study design issues -

1. Most studies examined an intervention and examine the effects of weight changes on outcomes. However, the potential bias from the confounding between the intervention and weight change may not have been entirely removed, even after adjustment for the intervention.

2. Effect modification by baseline patient characteristics was not always accounted for.

3. Most studies modeling outcomes considered static values for weight change and for confounders such as glycemic control. Methods for time varying covariates for longitudinal data would be more appropriate to accurately model the dynamic nature of these relationships.
4. The relationships between outcomes and weight change likely depend on the timing of measurement relative to the duration of the disease and type and duration of treatment at time of measurement. The choice of index date for pre/post studies varied and may be critical to the effects found and their interpretation.

Weight change measurement issues -

1. There was wide variation in the way weight change was measured, and the functional form (eg, linearity) of the relationship may depend on the definition used.

2. Various studies relied on self-reported or perception of weight change and others on clinical records. The reporting source may affect the nature of the relationship of weight change and outcomes.

Outcome measurement issues -

1. There was wide variation in the way glycemic control and cost were measured, and the functional form (eg, linearity) of the relationship may depend on the definition used.

2. The period of evaluation of outcomes varied (eg, 12 months or 24 months). There may be different effects of weight change on short vs long-term outcomes.

\section{Limitations}

This review was conducted using predefined eligibility criteria and conformed to Preferred Reporting Items for

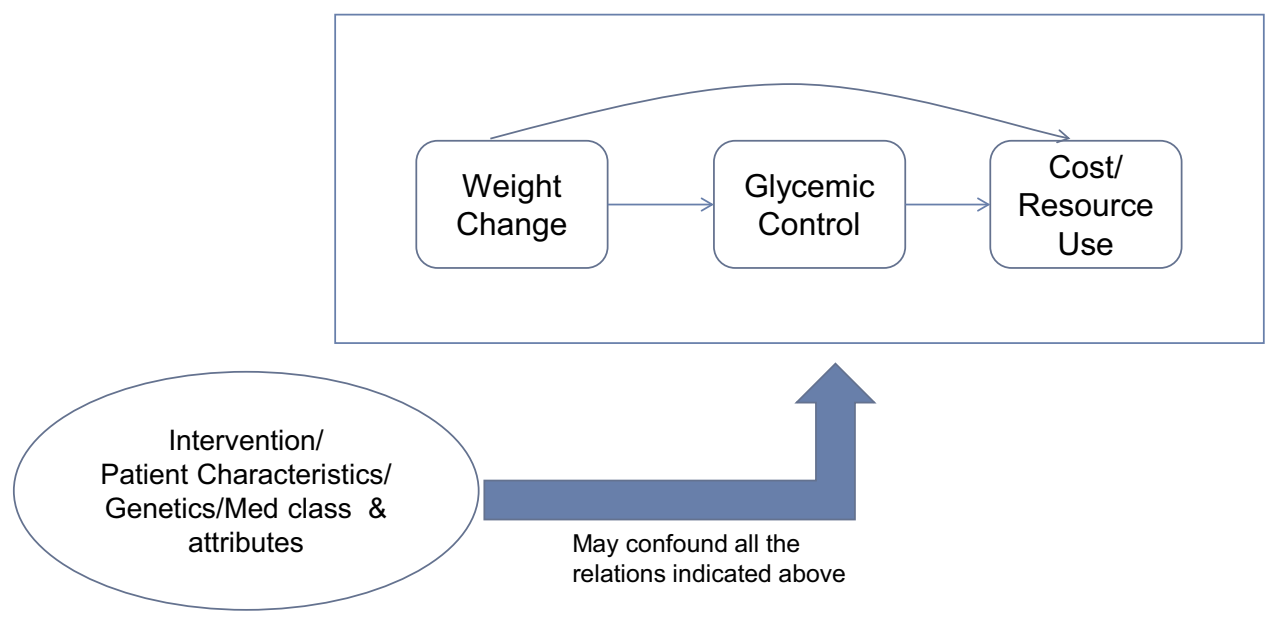

Figure 3 Nature of relationships between weight loss and health outcomes. 
Systematic Reviews and Meta-Analyses (PRISMA) guidelines, which contributes to the strength of the conclusions. However, limitations to this methodology include 1) restriction to articles published in the study period, and 2) the potential not to include articles that were lacking in the keywords used in the search but that did address the relationships of interest. Other limitations with respect to generalizability of the data retrieved may have resulted from the various populations studied by the relevant articles (eg, claims databases, national polls), and the methodological limitations outlined above. None of the studies directly evaluated beta-cell function and weight loss, a result that may have occurred because of the parameters used in our literature search. However, weight loss is known to directly impact insulin sensitivity, and to preserve beta-cell function. Where this review demonstrated inconsistent relationships between weight loss and glycemic control, relationships between weight loss and insulin sensitivity or beta-cell function may be more robust. Weight loss is generally associated with an improvement in whole-body insulin sensitivity and betacell function. ${ }^{65,66}$

\section{Conclusion}

This literature review and critical analysis describe the current state of the medical literature with respect to the association between weight change and the outcomes of glycemic control and cost/resource use in patients with T2DM. Generally, the studies were consistent in that weight loss/stability appeared positively associated with cost savings and that weight gain was negatively associated with cost savings. Improved study designs are required to isolate the effects of weight change on glycemic control and on cost/resource use, particularly with respect to potential biases that may occur because of differences in baseline characteristics of study patients, weight loss interventions, and the measurement of changes in these parameters and their relationships over time. Future conduct of real-world studies may advance our understanding of the incremental benefits of weight loss in T2DM patients.

\section{Acknowledgments}

The authors acknowledge Dr. Lisa M. Korst, AMF Consulting, who was funded by Novo Nordisk, Inc. for manuscript preparation and editorial assistance.

\section{Author Contributions}

All authors made a significant contribution to the work reported, whether that is in the conception, study design, execution, acquisition of data, analysis and interpretation, or in all these areas; took part in drafting, revising or critically reviewing the article; gave final approval of the version to be published; have agreed on the journal to which the article has been submitted; and agree to be accountable for all aspects of the work.

\section{Funding}

Funding for this study was provided by Novo Nordisk, Inc, USA.

\section{Disclosure}

Dr. Fridman is an employee of AMF Consulting, USA, and was contracted by Novo Nordisk, Inc. Dr Fridman reports personal fees from NovoNordisk, during the conduct of the study; personal fees from GSK, Jazz Pharmaceuticals, Shire, CSL Behring, Arena Pharmaceuticals, and Sage Therapeutics, outside the submitted work. Ms. Lucas and Drs. Paprocki, Dang-Tan, and Iyer are employees of Novo Nordisk, Inc. Dr Paprocki is a stockholder of Novo Nordisk, Inc. Although employees of Novo Nordisk were involved in the design, collection, analysis, interpretation, and fact checking of information, the content of this manuscript, the interpretation of the data, and the decision to submit the manuscript for publication was made by the authors independently. The authors report no other conflicts of interest in this work.

\section{References}

1. American Diabetes Association. Economic costs of diabetes in the U.S. in 2017. Diabetes Care. 2018;41(5):917-928. doi:10.2337/dci18-0007

2. Bommer C, Sagalova V, Heesemann E, et al. Global economic burden of diabetes in adults: projections from 2015 to 2030. Diabetes Care. 2018;41(5):963-970. doi:10.2337/dc17-1962

3. International Diabetes Federation (IDF). IDF Diabetes Atlas, 8th edition. 2017. Available at: http://www.diabetesatlas.org/. Accessed June $8,2020$.

4. Centers for Disease Control and Prevention. National Diabetes Statistics Report, 2017. Atlanta, GA: Centers for Disease Control and Prevention, U.S. Dept of Health and Human Services; 2017. Available at: https://www.cdc.gov/features/diabetes-statistic-report/ index.html. Accessed June 8, 2020.

5. Davies MJ, D'Alessio DA, Fradkin J, et al. Management of hyperglycemia in type 2 diabetes, 2018. A consensus report by the American Diabetes Association (ADA) and the European Association for the Study of Diabetes (EASD). Diabetes Care. 2018;41(12):2669-2701. 
6. Choy S, Kjellsson MC, Karlsson MO, de Winter W. Weight-HbA1cInsulin-Glucose model for describing disease progression of type 2 diabetes. CPT Pharm Syst Pharmacol. 2016;5(1):11-19.

7. Provilus A, Abdallah M, McFarlane SI. Weight gain associated with antidiabetic medications. Therapy. 2011;8(2):113-120.

8. Agency for Healthcare Research and Quality (AHRQ). Diabetes medications for adults with type 2 diabetes: an update. Comparative Effectiveness Review Number 173. AHRQ Publication No. 16EHC013-EF.2016. Available at: https://www.ncbi.nlm.nih.gov/ books/NBK362863/. Accessed June 8, 2020.

9. Gagliardi L, Wittert G. Management of obesity in patients with type 2 diabetes mellitus. Curr Diabetes Rev. 2007;3(2):95-101.

10. Colagiuri S. Diabesity: therapeutic options. Diabetes Obes Metab. 2010;12(6):463-473.

11. Lau DCW, Teoh H. Current and emerging pharmacotherapies for weight management in prediabetes and diabetes. Can J Diabetes. 2015;39(5):S134-S141. doi:10.1016/j.jcjd.2015.10.001

12. Stumvoll M, Goldstein BJ, van Haeften TW. Type 2 diabetes: principles of pathogenesis and therapy. Lancet. 2005;365(9467):13331346. doi:10.1016/S0140-6736(05)61032-X

13. Arksey H, O’Malley L. Scoping studies: towards a methodological framework. Int J Soc Res Methodol. 2005;8(1):19-32. doi:10.1080/ 1364557032000119616

14. Preferred Reporting Items for Systematic Reviews and MetaAnalyses (PRISMA). Flow diagram. Available at: http://prisma-state ment.org/documents/PRISMA\%202009\%20flow\%20diagram.pdf. Accessed June 8, 2020.

15. McEwan P, Evans M, Kan H, Bergenheim K. Understanding the inter-relationship between improved glycaemic control, hypoglycaemia and weight change within a long-term economic model. Diabetes Obes Metab. 2010;12(5):431-436. doi:10.1111/j.1463-1326.2009. 01184.x

16. McAdam-Marx C, Bellows BK, Unni S, et al. Determinants of glycaemic control in a practice setting: the role of weight loss and treatment adherence (The DELTA Study). Int J Clin Pract. 2014;68 (11):1309-1317. doi:10.1111/ijcp.12502

17. McAdam-Marx C, Bellows BK, Unni S, et al. Impact of adherence and weight loss on glycemic control in patients with type 2 diabetes: cohort analyses of integrated medical record, pharmacy claims, and patientreported data. J Manag Care Spec Pharm. 2014;20(7):691-700.

18. Aucott LS, Philip S, Avenell A, Afolabi E, Sattar N, Wild S, on behalf of the Scottish Diabetes Research Network Epidemiology Center. Patterns of weight change after the diagnosis of type 2 diabetes in Scotland and their relationship with glycaemic control, mortality and cardiovascular outcomes: a retrospective cohort study. BMJ Open. 2016;6(7):e010836.

19. Blonde L, Pencek R, MacConell L. Association among weight change, glycemic control, and markers of cardiovascular risk with exenatide once weekly: a pooled analysis of patients with type 2 diabetes. Cardiovasc Diabetol. 2015;14(1):12. doi:10.1186/s12933014-0171-2

20. Bron M, Wilson C, Fleck P. A post hoc analysis of HbAlc, hypoglycemia, and weight change outcomes with alogliptin vs glipizide in older patients with type 2 diabetes. Diabetes Ther. 2014;5(2):521534.

21. Carter S, Clifton PM, Keogh JB. The effects of intermittent compared to continuous energy restriction on glycaemic control in type 2 diabetes; a pragmatic pilot trial. Diabetes Res Clin Pract. 2016;122:106-112. doi:10.1016/j.diabres.2016.10.010

22. Chen JF, Chang CM, Kuo MC, Tung SC, Tsao CF, Tsai CJ. Impact of baseline body mass index status on glucose lowering and weight change during sitagliptin treatment for type 2 diabetics. Diabetes Res Clin Pract. 2016;120:8-14.

23. Cohen O, Norymberg C, Neumann E, Dekel H. Weight gain in type 2 diabetes mellitus-not all uphill. Diabetes Res Clin Pract. 2008;79 (1):128-132. doi:10.1016/j.diabres.2007.07.010
24. Davies MJ, Derezinski T, Pedersen CB, Clauson P. Reduced weight gain with insulin detemir compared to NPH insulin is not explained by a reduction in hypoglycemia. Diabetes Technol Ther. 2008;10 (4):273-277. doi:10.1089/dia.2008.0282

25. Davies MJ, Donnelly R, Barnett AH, Jones S, Nicolay C, Kilcoyne A. Exenatide compared with long-acting insulin to achieve glycaemic control with minimal weight gain in patients with type 2 diabetes: results of the Helping Evaluate Exenatide in patients with diabetes compared with Long-Acting insulin (HEELA) study. Diabetes Obes Metab. 2009;11(12):1153-1162. doi:10.1111/j.14631326.2009.01154.x

26. Del Prato S, Fleck P, Wilson C, Chaudhari P. Comparison of alogliptin and glipizide for composite endpoint of glycated haemoglobin reduction, no hypoglycaemia and no weight gain in type 2 diabetes mellitus. Diabetes Obes Metab. 2016;18(6):623-627.

27. Dornhorst A, Lüddeke HJ, Sreenan S, et al, on behalf of the PREDICTIVE Study Group. Insulin detemir improves glycaemic control without weight gain in insulin-naïve patients with type 2 diabetes: subgroup analysis from the PREDICTIVETM study. Int $J$ Clinical Pract. 2008;62(4):659-665. doi:10.1111/j.1742-1241. 2008.01715.x

28. Duane J, Conway W. Weight management in basal-bolus insulin therapy for type 2 diabetes mellitus: the Deep South Diabetes Program. Insulin. 2008;3(2):95-108. doi:10.1016/S1557-0843(08) 80020-6

29. Feldstein AC, Nichols GA, Smith DH, Rosales AG, Perrin N. Weight change and glycemic control after diagnosis of type 2 diabetes. J Gen Int Med. 2008;23(9):1339-1345. doi:10.1007/ s11606-008-0681-2

30. Feng P, Yu DM, Chen LM, et al, for the Clinical Cooperation Group of Liraglutide in Chinese Type 2 Diabetes. Liraglutide reduces the body weight and waist circumference in Chinese overweight and obese type 2 diabetic patients. Acta Pharmacol Sin. 2015;36 (2):200-208. doi:10.1038/aps.2014.136

31. Fonseca V, McDuffie R, Calles J, et al. for the ACCORD Study Group. Determinants of weight gain in the Action to Control Cardiovascular Risk in Diabetes trial. Diabetes Care. 2013;36 (8):2162-2168. doi:10.2337/dc12-1391

32. Glass LC, Qu Y, Lenox S, et al. Effects of exenatide versus insulin analogues on weight change in subjects with type 2 diabetes: a pooled post hoc analysis. Curr Med Res Opin. 2008;24(3):639-644. doi:10.1185/030079908X260862

33. Harayama T, Yoshida T, Yoshioka K, et al. Correlation between weight loss and improvement of diabetes mellitus among obese type 2 diabetic patients. Diabetol Int. 2013;4(2):132-137. doi:10.1007/s13340-013-0107-1

34. Horton ES, Silberman C, Davis KL, Berria R. Weight loss, glycemic control, and changes in cardiovascular biomarkers in patients with type 2 diabetes receiving incretin therapies or insulin in a large cohort database. Diabetes Care. 2010;33(8):1759-1765. doi:10.2337/dc092062

35. Huizinga MM, Niswender KD, Gebretsadik T, Rothman RL, Shintani AK, Elasy TA. Insulin use and weight maintenance in well-controlled type 2 diabetes: a prospective cohort study. Obesity. 2008;16 (8):1933-1937.

36. Jacob AN, Salinas K, Adams-Huet B, Raskin P. Weight gain in type 2 diabetes mellitus. Diabetes Obes Metab. 2007;9(3):386-393. doi:10.1111/j.1463-1326.2006.00622.x

37. Jacob S, Rabbia M, Meier MK, Hauptman J. Orlistat $120 \mathrm{mg}$ improves glycaemic control in type 2 diabetic patients with or without concurrent weight loss. Diabetes Obes Metab. 2009;11(4):361371. doi:10.1111/j.1463-1326.2008.00970.x

38. Janghorbani M, Amini M, Salehi-Marzijarani M. Weight change, blood pressure, lipids and glycemic control among patients with type 2 diabetes. Ann Nutr Metab. 2011;58(2):141-149. doi:10.1159/ 000327912 
39. Jansen HJ, Hendriks JC, De Galan BE, Penders G, Tack CJ, Vervoort G. Contribution of change in glycosylated haemoglobin to insulin-associated weight gain: results of a longitudinal study in type 2 diabetic patients. Endocr. 2011;39(2):190-197. doi:10.1007/s12020-010-9423-4

40. McAdam-Marx C, Mukherjee J, Bellows BK, et al. Evaluation of the relationship between weight change and glycemic control after initiation of antidiabetic therapy in patients with type 2 diabetes using electronic medical record data. Diabetes Res Clin Pract. 2014;103 (3):402-411. doi:10.1016/j.diabres.2013.12.038

41. Neiberg RH, Wing RR, Bray GA, et al. and the Look AHEAD Research Group. Patterns of weight change associated with longterm weight change and cardiovascular disease risk factors in the Look AHEAD study. Obesity. 2012;20(10):2048-2056. doi:10.1038/ oby. 2012.33

42. Nori Janosz KE, Koenig Berris KA, Leff C, et al. Clinical resolution of type 2 diabetes with reduction in body mass index using meal replacement based weight loss. Vasc Dis Prev. 2008;5(1):17-23. doi:10.2174/1567270000805010003

43. Umpierrez GE, Pantalone KM, Kwan AYM, Zimmermann AG, Zhang N, Fernández Landó L. Relationship between weight change and glycaemic control in patients with type 2 diabetes receiving onceweekly dulaglutide treatment. Diabetes Obes Metab. 2016;18 (6):615-622. doi:10.1111/dom.12660

44. Watson L, Wilson BP, Alsop J, Kumar S. Weight and glycaemic control in type 2 diabetes: what is the outcome of insulin initiation? Diabetes Obes Metab. 2011;13(9):823-831. doi:10.1111/j.14631326.2011.01413.x

45. Wing RR, Lang W, Wadden TA, et al. for the Look AHEAD Research Group. Benefits of modest weight loss in improving cardiovascular risk factors in overweight and obese individuals with type 2 diabetes. Diabetes Care. 2011;34(7):1481-1486. doi:10.2337/dc102415

46. Zhang Q, Zhao X, Chen M, Fang Z, Chen Y, Wang Y. Weight gain and changes in plasma adiponectin and leptin concentrations after 12-month insulin intensive therapy for Chinese male patients with newly diagnosed type 2 diabetes. Obes Res Clin Pract. 2016;10 (5):553-563. doi:10.1016/j.orcp.2015.09.005

47. Zinman B, Schmidt WE, Moses A, Lund N, Gough S. Achieving a clinically relevant composite outcome of an $\mathrm{HbA1c}$ of $<7 \%$ without weight gain or hypoglycaemia in type 2 diabetes: a meta-analysis of the liraglutide clinical trial programme. Diabetes Obes Metab. 2012;14(1):77-82.

48. Franz MJ, Boucher JL, Rutten-Ramos S, VanWormer JJ. Lifestyle Weight-Loss Intervention Outcomes in Overweight and Obese Adults with Type 2 Diabetes: A Systematic Review and Meta-Analysis of Randomized Clinical Trials. J Acad Nutr Diet. 2015;115(9):14471463. doi:10.1016/j.jand.2015.02.031

49. Gummesson A, Nyman E, Knutsson M, Karpefors M. Effect of weight reduction on glycated haemoglobin in weight loss trials in patients with type 2 diabetes. Diabetes Obes Metab. 2017;19 (9):1295-1305. doi:10.1111/dom.12971

50. Nichols GA, Bell K, Kimes TM, O'Keeffe-Rosetti M. Medical care costs associated with long-term weight maintenance versus weight gain among patients with type 2 diabetes. Diabetes Care. 2016;39:19811986.

ClinicoEconomics and Outcomes Research

\section{Publish your work in this journal}

ClinicoEconomics and Outcomes Research is an international, peerreviewed open-access journal focusing on Health Technology Assessment, Pharmacoeconomics and Outcomes Research in the areas of diagnosis, medical devices, and clinical, surgical and pharmacological intervention. The economic impact of health policy and health systems
51. Davis WA, Bruce DG, Davis TME. Economic impact of moderate weight loss in patients with type 2 diabetes: the Fremantle Diabetes Study. Diabet Med. 2011;28(9):1131-1135.

52. Mohamed AF, Zhang J, Johnson FR, et al. Avoidance of weight gain is important for oral type 2 diabetes treatments in Sweden and Germany: patient preferences. Diabetes Metab. 2013;39:397-403.

53. Mukherjee J, Sternhufvud C, Smith N, et al. Association between weight change, clinical outcomes, and health care costs in patients with type 2 diabetes. J Manag Care Spec Pharm. 2016;22(5):449-466.

54. Bell K, Parasuraman S, Shah M, et al. Economic implications of weight change in patients with type 2 diabetes mellitus. Am J Manag Care. 2014;20:e320-e329.

55. Blak BT, Rigney U, Sternhufvud C, Davis J, Hammar N. Weight change and healthcare resource use in English patients with type 2 diabetes mellitus initiating a new diabetes medication class. Int J Clin Pract. 2016;70(1):45-55.

56. Yu AP, Wu EQ, Birnbaum HG, et al. Short-term economic impact of body weight change among patients with type 2 diabetes treated with antidiabetic agents: analysis using claims, laboratory, and medical record data. Curr Med Res Opin. 2007;23:2157-2169.

57. Meads DM, Hulme CT, Hall P, Hill AJ. The cost-effectiveness of primary care referral to a UK commercial weight loss programme. Clin Obes. 2014;4(6):324-332.

58. Thorpe KE, Yang Z, Long KM, Garvey WT. The impact of weight loss among seniors on Medicare spending. Health Econ Rev. 2013;3(1):1-6.

59. Trueman P, Haynes SM, Felicity Lyons G, et al. Long-term costeffectiveness of weight management in primary care. Int J Clin Pract. 2010;64(6):775-783.

60. Sabale U, Bodegard J, Svennblad B, et al. Weight change patterns and healthcare costs in patients with newly-diagnosed type-2 diabetes in Sweden. Prim Care Diabetes. 2017;11(3):217-225.

61. Duong JK, de Winter W, Choy S, et al. The variability in beta-cell function in placebo-treated subjects with type 2 diabetes: application of the weight-HbAlc-insulin-glucose (WHIG) model. $\mathrm{Br} J$ Clin Pharmacol. 2017;83(3):487-497.

62. Pappachan JM, Viswanath AK. Medical management of diabesity: do we have realistic targets? Curr Diab Rep. 2017;17(1):4.

63. DerSarkissian M, Bhak RH, Huang J, et al. Maintenance of weight loss or stability in subjects with obesity: a retrospective longitudinal analysis of a real-world population. Curr Med Res Opin. 2017;33(6):1105-1110.

64. Karkare S, Fridman M, Dang-Tan T, et al. Effect of weight change on economic outcomes among persons with type 2 diabetes mellitus in the United States: beyond glycemic control. J Manag Care Spec Pharm. 2019;25(6):658-668.

65. Hardy OT, Czech MP, Corvera S. What causes the insulin resistance underlying obesity? Curr Opin Endocrinol Diabetes Obes. 2012;19 (2):81-87.

66. Ferrannini E, Camastra S, Gastaldelli A, et al. $\beta$-cell function in obesity. Diabetes. 2004;53(Supp13):S26-S33. organization also constitute important areas of coverage. The manuscript management system is completely online and includes a very quick and fair peer-review system, which is all easy to use. Visit $\mathrm{http}: / /$ www.dovepress.com/testimonials.php to read real quotes from published authors.

\section{Dovepress}

